\title{
A Critical Reflection on Housing Market Area Definition in England
}

\author{
Stephen Hincks \\ $\&$ \\ Mark Baker \\ Centre for Urban Policy Studies, \\ School of Environment and Development \\ Planning, \\ University of Manchester, \\ Oxford Road, \\ Manchester, \\ M13 9PL \\ Stephen.hincks@manchester.ac.uk \\ Mark.baker@manchester.ac.uk
}

A version of this paper was published in Housing Studies (2012) (Volume 12 Issue 7) p873897. 


\begin{abstract}
The adoption of administrative boundaries as approximations of housing markets has long restricted the scope for housing market analysis and planning policy development to be undertaken within a functional housing market framework in England. This has prompted consideration of the value of deriving Housing Market Areas (HMAs) to underpin the development of housing market intelligence for planning and policy purposes. Drawing on a case study of North West England, this paper critically reviews alternative approaches that have been used to define HMAs. The review highlights that in practice technical and methodological constraints have restricted the operationalisation of an idealised conceptualisation of HMAs.
\end{abstract}




\section{A Critical Reflection on Housing Market Area Definition in England}

\section{Introduction}

The adoption of administrative boundaries as approximations of housing markets has long restricted the scope for housing market analysis and planning policy development to be undertaken within a functional housing market framework in England. Drawing on lessons from Scotland', the previous Labour Government published guidance that supported the use of sub-regional Housing Market Areas (HMAs) when undertaking Strategic Housing Market Assessments (SHMAs) (e.g. DTZ Pieda, 2004). Thereafter, research focusing on defining HMAs in England accelerated at pace (Bibby, 2005; Coombes et al., 2006; Brown and Hincks, 2008; Coombes, 2009).

Despite the recent change to the political stripe of government in the UK ${ }^{\mathrm{ii}}$, the potential for applying the HMA framework in developing functional housing market intelligence in England remains strong. Since assuming office in 2010 the Coalition Government has introduced a number of changes to the planning system in England. At national level, Planning Policy Statements (PPSs) - introduced as part of the 2004 planning reforms - are to be replaced by a National Planning Policy Framework (NPPF) that intends to condense existing national planning guidance into a single streamlined guidance document (CLG, 2011). Significantly, the draft NPPF still requires local authorities - working in partnership with neighbouring authorities where necessary - to prepare SHMAs. The implication of this is that the HMA framework remains a viable tool to underpin SHMAs and the development of wider functional housing market intelligence. The aim of this article is to reflect on recent attempts to define HMAs in England drawing on evidence from a study iii undertaken for the National Housing and Planning Advice Unit. ${ }^{\text {iv }}$ The next section outlines a conceptualisation of HMAs that seeks to establish an idealised framework for defining HMAs. This results in the emergence of a typology of possible HMA approaches. The review then critically explores how the definition of HMAs have been conceptualised and operationalised in practice using a case study of North West England. The final section reflects on the implications of the review for defining HMAs in England.

\section{Conceptualising Housing Market Areas}

The housing market area (HMA) approach is embedded in the access-space model of urban spatial structure. This framework illustrates how, under conditions of perfect competition, the household chooses its residential location to maximise its utility, balancing the costs of location against the advantages of cheaper land with increasing distance from the centre where employment is assumed to be concentrated (Wingo, 1961; Alonso, 1964). The model has a number of limitations. Its application is moderated by the outcomes of planning activity, including the location of social housing and green belt land (Jones and Watkins 2009). It also neglects household preferences and variations in housing type, quality and stock. Nevertheless, the assumptions of the access-space model with regard to the tradeoff between residential location, house prices and journey to work distance suggests that a HMA framework should, if defined appropriately, have the capacity to capture the spatial structure of sub-regional housing markets. Based on the logic here, consideration needs to be given to housing market processes that shape and reflect housing supply and demand interactions at sub-regional level and give due consideration to the interaction of residential and workplace locations. 


\section{The Role of Housing Market Search Patterns}

Housing market search is the first stage in the household migration process (Jones, 2002). Wheaton (1990) proposes a housing market matching model which provides a framework for conceptualising the relationship between housing turnover, search and price in the owner-occupied market. In the short-run, the number of households is assumed to be fixed and households will periodically choose to relocate to a new dwelling as households become 'mismatched' with their existing unit. Wheaton suggests that dissatisfaction with their existing unit motivates the household to invest significant amounts of time and resources into searching for more suitable housing units and that sellers, themselves engaged in market search, can hold two units; the first being their 'old' unit and the second being their 'new' unit.

Market search is influenced by spatial and structural considerations. Advances in behavioural economics (e.g. Simon, 1984) have demonstrated that individual household search patterns vary in scope and geographical focus according to different choices, constraints and available opportunities - influenced by the life-cycle of the household which shape search behaviour (Marsh and Gibb, 1997; de Groot et al, 2011). The adoption of alternative search strategies have the potential to create more contained, or more diffuse, search areas as Fielding's (1992) study of South East England's 'escalator region' effect demonstrates. The scope of the alternative search strategies is influenced by the process of knowledge acquisition. By gathering information, individuals narrow a large sample of properties into a sub-sample of ideal properties (Paraschiv and Chenavaz, 2011). The effect is that households become 'matched' to a unit according to their requirements. It is suggested that market search patterns can expose areas of high search intensity that can form the nuclei of potential HMAs (Maclennan, 1992).

The challenge, however, comes in operationalising the concept of market search as a defining feature of HMAs. An obvious practical problem in capturing search patterns is that a large qualitative data collection strategy would need to be adopted to provide detailed evidence of household search patterns (Brown and Hincks, 2008). Related to this issue are a number of other equally important questions. How should variation in search behaviour between households be accommodated in the definitional process? How should intended and actual moving behaviour be accommodated in the HMA search definition process? How should variation in search behaviour between sectors be accommodated in the definition process?

\section{The Role of Spatial Arbitrage}

Although valuable for capturing the nodes around which to initially form HMAs, search patterns alone would fail to capture the key defining feature of housing markets: arbitrage. In terms of housing market functioning (in the owner-occupied market), in the process of buying and selling a property at a uniform price (arbitrage), buyers consider transactions at any point in a given geographical area to be an appropriate substitute (Jones, 2002:552). The fact that in housing markets the product is immobile and the consumers are mobile means that a housing market is created whenever an individual wishes to purchase a residential property, generally accompanied by a move from an occupied property to take up residence in another property (Jones and Watkins, 2009). 
The result of this process is migration. The migration flow is an outcome of the interaction between the supply of, and demand for, housing. Buyers demand certain types of housing with certain characteristics in specific locations and their behaviour is influenced by a range of factors including past experiences, social and cultural norms, expectations, and the availability of relevant information (Paraschiv and Chenavaz, 2011). Supply is undertaken within the limits of a planning framework that is characterised by specific planning policies, cultures, funding regimes and delivery mechanisms (e.g. section 106 agreements). Supply is also shaped by the relationships and power dynamics that exist between institutions and agents operating in the supply chain (see Healey, 1994; Healey, 1998) and the practices of developers and other market agents (e.g. land banking and speculative development) (see Adams and Watkins, 2002; Carmona et al., 2003). It has been contended that HMA boundaries should be drawn through areas where there are few movements and hence low spatial arbitrage (Jones, 2002).

However, there are problems with applying the arbitrage principle. If we take the owneroccupied market, the majority of transactions will be between buyers and sellers. Each unit will form both an origin (buyer-end of the flow) and a destination (seller-end of the flow). However, there will be instances in which households leave the owner-occupied sector to enter the rental sector in which case recording arbitrage becomes problematic as two markets interact. In light of this, recent calls for greater consideration to be given to the housing system as a whole hold weight (e.g. Ferrari, 2011). In addition, migration patterns themselves are not a pure measure of demand. Rather migration patterns, employed in isolation of compatible transaction data, only capture effective or realised demand.

\section{The Role of Commuting between Home and Work}

Returning to the assumptions of the access-space model, in travelling to the centre of the city it is assumed that the household bears higher transport costs but is compensated by lower housing costs meaning that the household trades off housing costs with transport costs. Therefore, each household is assumed to consider both housing and transport costs equally in their location decision-making process. Under such assumptions, as household income increases so does its demand for space. Consequently, higher-income households often locate further from the city centre which helps to explain - in conjunction with the effect of transport costs - population decentralisation and sprawl.

There is an abundance of research evidence that demonstrates the effects of changing attitudes towards the work-life balance and developments in technology, transport, and infrastructure on the relationship between home and work (Hincks and Wong, 2010). Indeed, Ommeren et al (1997) found that rather than accepting a residence-job combination which offers a unique optimal commuting distance, workers will often accept a wide range of combinations of residential and workplace locations as they search for better jobs and residencies and a balance between accessibility and quality of life (also see Rouwendal, 2004). In defining HMAs, commuting to the local employment centre helps to drive local housing markets and the associated employment is the source of income that underpins demand in the housing market (Jones et al., 2010). As a result, it is argued that the limit of HMA boundaries can be determined by the travel patterns of the longest distance commuters (Jones et al., 2010). However, as Jones et al (2010:8) point out, due to 
the long-term equilibrium view of the housing market offered by the access-space model, '...HMAs defined by commuting patterns are best viewed as a framework within which spatial housing market processes operate'.

\section{The Issue of Scale}

A key consideration in the definition of HMAs is the question of scale and how housing market processes operate within and across different spatial scales. It has long been acknowledged that urban areas operate as a series of submarkets (Grigsby, 1963; Rothenberg et al., 1991). Differences in supply and demand interactions mean that price differences will exist for different housing types, sizes and so on, reflecting short-run supply and demand inelasticity leading to different submarket structures (Maclennan, 1982; Watkins, 2001; Jones et al., 2003, 2004, 2005). The price of a standardised dwelling will be the same within submarkets but the price will differ from other parts of the market (Jones et al., 2004:272).

It is contended that HMAs and submarkets are interconnected with HMAs providing a subregional framework within which submarkets are nested. Submarkets have been shown to have a high degree of migration self-containment reflecting limitations in information and comparatively high transaction costs within housing markets (Jones et al., 2005). As a result, constraints are imposed on arbitrage which means that price differentials are retained within different parts of the HMA. However, a tension exists in distinguishing between different tiers of housing markets from sub and pan-regional HMAs to submarkets. It is argued that HMAs should equate with either a single settlement, or a group of contiguous settlements (Jones et al., 2005). Therefore, in sub-regional housing market terms, smaller settlements may best be characterised as an extension of a larger settlement's HMA meaning that HMAs can be disaggregated into lower-tier markets, whether in the form of a sub-tier of HMAs or (below those) submarkets.

\section{Unpacking the Conceptualisation of Housing Market Areas}

The conceptualisation outlines the principles on which HMA delineation would ideally be developed as proposed by Jones et al (2010). Having identified HMA nodes - underpinned by market search principles - the conceptualisation illustrates the value of using commuting patterns to define the limit of upper-tier HMAs based on long-distance commuting. Ultimately, long-distance commuting captures those individuals and households that drive housing markets beyond the 'local' because of their activity in the labour market.

Following the identification of the spatial limit of upper-tier HMAs using a high level of commuting self-containment - a level that would need to be determined empirically through testing - linked transaction and migration patterns could then be used to define high-migration self-contained market areas - a level that would again need to be determined empirically. These lower-tier HMAs would be defined to capture patterns of high intra-HMA arbitrage and low inter-HMA arbitrage. This would serve to create a twotier HMA system. Housing market functioning, particularly in the short-term, would be smoothed away in the upper-tier HMAs as the relationship between home and work dominates meaning that these upper-tier HMAs would act as 'strategic' policy areas. In contrast, the sub-tier HMAs would be much more likely to reflect the idiosyncratic nature of housing market functioning at a more localised level reflecting the interaction of supply and 
demand regimes (Jones et al., 2010). The sub-tier HMAs would capture the heterogeneity of housing and the constraints placed on spatial arbitrage by migration patterns. It is this constraint on spatial arbitrage - reflected through the localisation of migration - that drives the definition of the sub-tier HMAs. To test the validity of the sub-tier HMAs then, house price analysis could be used to determine that each adjacent sub-tier HMA had a statistically different price for the same standardised house. This reflects the assumption that prices within HMAs should tend to uniformity.

As a result, the sub-tier HMAs would function with, what Jones et al (2010:8) describe as, 'quasi-independence' from other parts of the upper-tier HMA. What this means is that subtier HMAs - due to constraints imposed on the process of spatial arbitrage - could function very differently from one another even though they might be part of the same upper-tier HMA. As Jones et al (2010:9) point out, spatial arbitrage has an effect but with a time-lag. This means that processes occurring within the upper-tier HMA can play out very differently within different sub-tier HMAs reflecting differential supply and demand regimes operating at the local level; the functionality of different neighbourhoods within sub-tier HMAs; and the structural attributes of the housing market (e.g. quality and type of housing). Therefore, the sub-tier HMAs would capture spatial variations in trends more effectively than the upper-tier HMAs and so would prove valuable for framing local housing market analyses. The message emerging from the conceptualisation is that housing market functioning is variegated and unevenness in the inputs and processes underpinning housing markets provides a local articulation of outcomes that affect the form, function and structure of housing markets in space and through time (Meen, 2001; Jones and Leishman, 2006; Jones and Watkins, 2009).

In reality, different constraints limit the application of the idealised approach outlined here. In England the exercise of defining HMAs has been plagued by uncertainty with different and often competing approaches emerging as a consequence (Coombes, 2009). Table 1 provides details of a typology of possible HMA approaches that recognises that different principles can be combined in different ways to create variations on the idealised approach. On the one hand, these variations might be defined without the adoption of conceptual, methodological and/or technical trade-offs leading to the development of an unconstrained approach. On the other hand, the definition of HMAs might be undertaken within the limits of conceptual, methodological and/or technical trade-offs resulting in the development of a constrained approach to HMA definition. 
Table 1: Typology of Possible HMA Approaches

\begin{tabular}{|c|c|c|c|}
\hline $\begin{array}{l}\text { Primary } \\
\text { Tenet }\end{array}$ & Secondary Tenet(s) & Description & Type \\
\hline \multicolumn{4}{|c|}{ Arbitrage-Driven Approach } \\
\hline \multirow{4}{*}{$\begin{array}{l}\text { Spatial } \\
\text { Arbitrage }\end{array}$} & Market Search \& Commuting & $\begin{array}{l}\text { Driven by the tenet of spatial arbitrage and } \\
\text { incorporates market search and commuting }\end{array}$ & $A(i)$ \\
\hline & Market Search & $\begin{array}{l}\text { Driven by the tenet of spatial arbitrage and } \\
\text { incorporates market search }\end{array}$ & A (ii) \\
\hline & Commuting & $\begin{array}{l}\text { Driven by the tenet of spatial arbitrage and } \\
\text { incorporates commuting }\end{array}$ & A (iii) \\
\hline & None & $\begin{array}{l}\text { Driven by the tenet of spatial arbitrage but does } \\
\text { not include any other components }\end{array}$ & A (iv) \\
\hline \multicolumn{4}{|c|}{ Market Search-Driven Approach } \\
\hline \multirow{4}{*}{$\begin{array}{l}\text { Market } \\
\text { Search }\end{array}$} & $\begin{array}{l}\text { Spatial Arbitrage \& } \\
\text { Commuting }\end{array}$ & $\begin{array}{l}\text { Driven by the tenet of market search and } \\
\text { incorporates spatial arbitrage and commuting }\end{array}$ & MS (i) \\
\hline & Spatial Arbitrage & $\begin{array}{l}\text { Driven by the tenet of market search and } \\
\text { incorporates spatial arbitrage }\end{array}$ & MS (ii) \\
\hline & Commuting & $\begin{array}{l}\text { Driven by the tenet of market search and } \\
\text { incorporates commuting }\end{array}$ & MS (iii) \\
\hline & None & $\begin{array}{l}\text { Driven by the tenet of market search but does } \\
\text { not include any other components }\end{array}$ & MS (iv) \\
\hline \multicolumn{4}{|c|}{ Commuting-Driven Approach } \\
\hline \multirow{4}{*}{ Commuting } & $\begin{array}{l}\text { Spatial Arbitrage \& Market } \\
\text { Search }\end{array}$ & $\begin{array}{l}\text { Driven by the tenet of commuting and } \\
\text { incorporates spatial arbitrage and market search }\end{array}$ & $C(i)$ \\
\hline & Spatial Arbitrage & $\begin{array}{l}\text { Driven by the tenet of commuting and } \\
\text { incorporates spatial arbitrage }\end{array}$ & C (ii) \\
\hline & Market Search & $\begin{array}{l}\text { Driven by the tenet of commuting and } \\
\text { incorporates market search }\end{array}$ & C (iii) \\
\hline & None & $\begin{array}{l}\text { Driven by the tenet of commuting but does not } \\
\text { include any other components }\end{array}$ & C (iv) \\
\hline
\end{tabular}

\section{Case Study Context and Research Questions}

Housing Market Areas have been defined across all of the English regions in recent years in large part because of the emphasis placed on the value of using HMAs to underpin Strategic Housing Market Assessments (SHMAs) and Strategic Housing Land Availability Assessments (SHLAAs) in government guidance. However, the North West region has emerged as something akin to England's HMA 'laboratory' in which competing definitions have been produced for a range of agencies (Ferrari et al., 2011). Extensive HMA definition exercises have been undertaken for Government Office North West (ECOTEC, 2006), the North West Development Agency (Brown and Hincks, 2008), and the North West Regional Assembly (Nevin Leather Associates et al., 2008) ${ }^{v}$. ECOTEC (consultant-led) was commissioned to define HMAs for the region to inform housing allocations. Brown and Hincks (academic-led) defined HMAs as part of a study to understand spatial interaction between housing and labour markets in the North West (see Hincks and Wong, 2010). The Nevin Leather Associates et al (combined consultant and academic) research was commissioned with the 
purpose of defining HMAs that could be used to undertake housing market assessments. These three studies offer complete coverage of the region by different HMA geographies, emerging as a result of different policy imperatives as well as variations in conceptual and methodological underpinnings (see Table 2). These conceptual and methodological components were critically reviewed against the idealised framework proposed for HMA delineation outlined above.

Table 2: Summary of North West HMA Studies

\begin{tabular}{|c|c|}
\hline Study & Description \\
\hline ECOTEC (2006) & $\begin{array}{l}\text { Uses travel-to-work patterns to define HMAs. The method identifies employment } \\
\text { centres of 5,000 people or more as 'core employment areas'. The wards from which } \\
10 \% \text { of workers travelling to each employment centre are determined and these were } \\
\text { taken to represent a HMA. Where one area of influence was completely included inside } \\
\text { another, or if there was a significant degree of overlap between areas these were } \\
\text { merged to form a single HMA. }\end{array}$ \\
\hline $\begin{array}{l}\text { Brown and } \\
\text { Hincks (2008) }\end{array}$ & $\begin{array}{l}\text { Uses an iterative algorithm based on information collected from estate agents, to } \\
\text { identify HMA cores, and a functional regionalisation of } 2001 \text { Census inter-ward } \\
\text { migration flows (based on the principle of the supply of and demand for housing) to } \\
\text { identify HMAs in North West England based on a } 70 \% \text { supply and demand-side self- } \\
\text { containment threshold. The approach uses aggregate migration patterns but any type } \\
\text { of migration dataset (e.g. moving groups) could be applied with the algorithm. }\end{array}$ \\
\hline $\begin{array}{l}\text { Nevin Leather } \\
\text { Associates et al } \\
\text { (2008) }\end{array}$ & $\begin{array}{l}\text { Uses Land Registry records to estimate a 'neighbourhood price' at post-code level for } \\
\text { each housing transaction in the North West. It is based on the idea that despite the } \\
\text { heterogeneity of housing and the impact this has on market form, 'price formation } \\
\text { effects' can be used to identify areas with similar house prices. The approach assumes } \\
\text { that prices can be explained by both the attributes of the property and its } \\
\text { neighbourhood as well as by sub-regional effects (hope value or expectations of future } \\
\text { capital appreciation). According to the approach, variations in the sub-regional effect } \\
\text { are indicative of variations in the price paid for a similar housing product and an } \\
\text { indication of the existence of different market areas. The study also applies commuting } \\
\text { and migration data and stakeholder knowledge to test the validity of the price defined } \\
\text { HMA boundaries. }\end{array}$ \\
\hline
\end{tabular}

Drawing on the conceptual debates covered earlier, a number of questions emerged that underpinned the review. How have the core tenets of HMA definition been applied in the North West studies? How have the HMA approaches been operationalised from a technical and methodological perspective in the North West studies? What are the spatial geographies of HMAs that emerge as a result of the adoption of different conceptual and methodological approaches in the region? It is to these questions that the paper will now turn.

\section{Reviewing the Application of the Core Tenets of Housing Market Area Definition}

This section will review the application of the core tenets of spatial arbitrage, market search, the home-work link, and issue of scale in defining HMAs in the three North West studies. Table 3 summarises the results of the review. 
Table 3: Summary of the North West Study Review

\begin{tabular}{|c|c|c|c|c|}
\hline Tenet & Feature & ECOTEC (2006) & $\begin{array}{c}\text { Brown and } \\
\text { Hincks (2008) }\end{array}$ & $\begin{array}{c}\text { Nevin leather } \\
\text { Associates et al } \\
\text { (2008) }\end{array}$ \\
\hline \multirow{2}{*}{ Spatial Arbitrage } & Transactions/Substitutability & - & S & $P$ \\
\hline & Migration & - & $P$ & $S$ \\
\hline \multirow{2}{*}{ Market Search } & Household Search Data & - & - & - \\
\hline & Market Intermediaries/Actors & - & $S$ & $S$ \\
\hline \multirow{2}{*}{ Commuting } & Commuting Patterns & $P$ & - & S \\
\hline & Travel-to-Work Areas & - & $S$ & - \\
\hline \multirow{2}{*}{ Scale } & Single Scale & - & * & $*$ \\
\hline & Multiple Scales & $*$ & - & - \\
\hline \multicolumn{2}{|c|}{ HMA Approach } & $\begin{array}{c}\text { (Constrained) } \\
\text { C (iv) }\end{array}$ & $\begin{array}{c}\text { (Constrained) } \\
\text { A (i) }\end{array}$ & $\begin{array}{c}\text { (Constrained) } \\
\text { A (i) }\end{array}$ \\
\hline
\end{tabular}

Notes

Refers to the Typology in Table 1

$\mathrm{P}$ - Primary defining tenet; $\mathrm{S}$ - Secondary defining tenet

- Limited/no obvious consideration given to the tenet

\section{The Application of Spatial Arbitrage}

Spatial arbitrage was found to have a variable role in the definition of HMAs in the three North West studies. In the ECOTEC (2006) study, limited consideration was given to the role of arbitrage in the housing market. However, there was evidence of the concept being explicitly considered in the Brown and Hincks (2008) and Nevin Leather Associates et al (2008) studies but being applied under constrained conditions.

The former approach used migration flows from the 2001 Census of Population to define HMAs based on the assumption that movers will substitute their dwellings with other dwellings and that the resulting migration patterns reflect the result of effective supply and demand regimes. In contrast, Nevin Leather Associates et al (2008) adopted an approach for defining HMAs that attempted to control for variations in property and neighbourhood characteristics by estimating a 'neighbourhood price'. This is assumed to have a systematic relationship to the property value mix in a neighbourhood (indicated by council tax band composition), and to social mix in a particular area (defined through the Census) (Bibby, 2005:2). The assumption was that dwelling prices could be explained by property and neighbourhood attributes to form a 'combined neighbourhood price' and by what the authors termed 'sub-regional effects' - additional factors that were not captured by dwelling and neighbourhood attributes but which helped to explain the price of a dwelling. In order to isolate the sub-regional effects, property and neighbourhood attributes were regressed against dwelling price. The estimated price was compared with the actual (observed) price and the residual was taken to represent the 'sub-regional effect'. The approach was grounded in the concept of substitutability which dictates that demanders be relatively indifferent between the entire 'bundle' of physical, locational and neighbourhood 
quality attributes that characterise competing housing units (Jones et al., 2004:272). In controlling for variations in price due to property and neighbourhood characteristics, it was assumed that the sub-regional effect indicated the existence of possible sub-regional HMAs.

Both studies explicitly recognised the role that spatial arbitrage plays in underpinning the functioning of housing markets. However, both studies faced problems in terms of the operationalisation of the concept. Spatial arbitrage is a measure of transactions through space. Jones (2002) delineated HMAs in West Central Scotland using transaction-based migration flows drawn from the Sasines database. The database records actual transactions and the characteristics of the property, the address, the sale price, the date of registration, and the origin of the mover over a ten-year period in Scotland. It is also a long-term dataset that contains a large sample of spatial transactions (approximately $95 \%$ of transactions are recorded). This makes it an ideal dataset for delineating HMAs based on the principle of spatial arbitrage. However, a Sasines-style database does not exist in England.

Consequently, Brown and Hincks' (2008) study was constrained by the fact that the approach did not consider actual transactions linked to moves which is needed to identify a spatial chain of substitution.

Nevin Leather Associates et al (2008) used Land Registry data to identify potentially substitutable properties. However, the approach also suffered from the absence of spatial transaction data. Indeed, the approach can be subjected to the same criticism as the Brown and Hincks (2008) study as actual transactions could not be linked in a spatial chain of substitution to define the boundaries of HMAs. In addition, the approach used house price analysis to broadly identify HMA boundaries which were then validated using migration and commuting patterns. This represents something of a departure from the conceptualisation outlined earlier which proposes that sub-tier HMA boundaries should ideally be defined through linked transaction and movement data and validated statistically using standardised house price analysis.

The implication is that both studies - whilst recognising the value of defining HMAs using the concept of spatial arbitrage - were constrained by methodological and technical challenges that restricted the operationalisation of the spatial arbitrage principle in a 'pure' form.

\section{The Application of Housing Market Search}

It is widely recognised that housing market search underpins residential mobility (Wheaton, 1990). However, the role of housing market search was overlooked in the ECOTEC (2006) study. In contrast, both Brown and Hincks (2008) and Nevin Leather Associates et al (2008) recognised the advantages of using market search to inform the definition of HMAs. However, market search formed a secondary tenet in both definition exercises with the two studies drawing on estate agent knowledge to 'reveal' market search patterns. Nevin Leather Associates et al used estate agent knowledge of market search to validate the price analysis exercise whilst Brown and Hincks used estate agent knowledge to identify core settlements around which to seed embryonic HMAs.

However, the use of market intermediaries to 'identify' search areas is problematic. As with buyers and sellers, market intermediaries do not have perfect knowledge of the market or 
of all those households searching for a property. Therefore, information is incomplete on prevailing search patterns. In addition, the consultation exercise in both studies only focused on the owner-occupied sector. If it is accepted that housing market systems need to be understood more fully due to interaction of movers between sectors (Ferrari, 2011), then the consultation exercise would need to be extended to include private rental companies and Registered Social Landlords (RSLs) ${ }^{\text {vi }}$ to reflect the search areas of current nonhomeowners who are searching in the owner-occupied sector but whose interests and practices are unlikely to be adequately captured by estate agent knowledge. The review demonstrated the absence of market search as the primary defining tenet of HMAs and its constrained use as a secondary tenet in two of the three North West studies.

\section{Consideration of Commuting between Home and Work}

The potential role played by commuting in defining HMAs was recognised in all three North West studies. In addition to estate agent consultation, Brown and Hincks used travel-towork-areas (TTWAs) to inform the choice of core settlements around which to seed HMAs. This was based on the assumption that HMAs and TTWAs serving the same geographical area should share boundaries of similar extent because the majority of households will simultaneously search for housing and jobs within their labour market area (Rouwendal, 2004). This assumption also featured in the Nevin Leather Associates et al study in which commuting patterns were used to validate house price derived HMA boundaries. In both studies, commuting formed a secondary tenet of HMA definition.

In contrast, commuting formed the primary tenet on which HMA boundaries were defined in the ECOTEC (2006) study. It was argued that '...travel-to-work patterns provide an important indicator of the economic linkages between areas...' (ECOTEC, 2006:8). The study usefully demonstrated the potential for applying commuting pattern analysis to understand the role that the interaction of home and work plays in driving the spatial structure of housing markets. However, commuting patterns are unable to capture the idiosyncratic nature of housing market functioning owing to the interaction of supply and demand regimes for housing and are unable to capture constraints placed on arbitrage in the housing market by migration patterns. Therefore, the approach is constrained by the narrow reliance on commuting - used in isolation from other processes - to define HMAs.

Commuting certainly featured in one form or another in all three of the North West studies. However, due to the use of competing conceptualisations and methodologies, there was significant variation in the application of commuting as a defining feature of the respective HMAs.

\section{Consideration of Scale}

The issue of scale featured prominently in the conceptual and methodological discussions of all three studies. The ECOTEC study found evidence of a two-tier HMA system across the metropolitan belt in the North West. Local sub-tier HMAs were defined across the region but for the Greater Manchester and Merseyside conurbations it was recognised that, in commuting terms, there was a strong empirical justification for defining two upper-tier HMAs - one for Merseyside and one for Greater Manchester - that captured the effects of long-distance commuting. Significantly, the study offers an insight into the value of adopting a multi-tiered HMA framework - as outlined in the conceptualisation - in which 
upper-tier HMAs are defined through the analysis of long-distance commuting (see Jones et al., 2010).

In considering the role of scale, Brown and Hincks (2008) recognised the potential existence of submarkets and that submarkets could affect the definition of HMAs. As Jones (2002) rightly points out, the distinction between submarkets and HMAs is not a matter of semantics as both housing market frameworks have their origins in the process of substitutability and the functioning of spatial arbitrage. HMAs reflect the outcome of internal spatial arbitrage and submarkets reflect the outcome of constraints placed on the arbitrage process. However, distinguishing between HMAs and submarkets is problematic because submarkets have been found to have relatively high self-containment levels in relation to migration flows (Jones et al., 2004, 2005). Brown and Hincks used the estate agent knowledge coupled with migration analysis to 'distinguish' between HMAs and submarkets. However, a limitation of the approach was that the statistical verification of the existence of submarkets was not undertaken.

Likewise, Nevin Leather Associates et al were explicit in their treatment of scale, recognising that HMAs should be defined on a sub-regional basis. Their definition of 'sub-regional' was informed by the analysis of softer factors - including the 'catchment areas' of existing subregional housing partnerships - in addition to harder statistical analysis of house price, commuting and migration data. Additionally - although not explicitly considered in the study - the standardised price modelling approach was useful for highlighting spatial variations in price structure through the localisation of housing market functioning. The modelling approach illustrated that constraints imposed on housing market adjustments for example to housing supply and demand regimes - and spatial arbitrage give rise to very different price structures across space and thus to the potential existence of different housing market structures in the form of sub-tier 'local' HMAs or, below those, submarkets (Jones et al., 2010).

\section{Technical and Methodological Considerations}

In addition to conceptual robustness, HMA definition is also underpinned by methodological and technical considerations. Debates around technical and methodological issues have the potential to marginalise non-technical stakeholders and can favour technocratic elites (Rydin, 2007). However, engaging with such technical debates is important in helping to open up the definitional process to wider scrutiny (Ferrari et al, 2011).

\section{Data Issues}

The definitions of HMAs developed by ECOTEC (2006) and Brown and Hincks (2008) were both primarily underpinned by 2001 origin-destination data (Table 4) collected through the Census. Special Workplace Statistics (SWS) capture commuting patterns and Special Migration Statistics (SMS) capture trends in migration. The SWS records the origin and destination of commuting between primary residential and workplace locations. Each commuting flow represents one person travelling-to-work in the labour market with each person participating in the labour market only included once. Similarly, the SMS compares the place of residence of persons/households in 2000 to their residence exactly one year later. 
An advantage of the SMS and SWS datasets is that the 2001 Census provides $100 \%$ coverage of migrants and commuters as recorded on the census date. The SWS and SMS datasets are the most complete origin and destination datasets available in the UK, at fine spatial scales, making them hugely advantageous over other datasets when defining functional areas. However, the SMS and SWS are only updated every ten years and are snapshots of commuting and migration patterns at a point in time ${ }^{\text {vii. }}$. In addition, techniques were adopted for disclosure control in the 2001 SMS and SWS datasets, which included 'pretabulation' and 'post-tabulation' adjustments and Small Cell Adjustment Methodology (SCAM) (see Stillwell and Duke-Williams, 2007). Therefore, the origin-destination data have been manipulated to ensure confidentiality and the effects of this manipulation are most pronounced at finer spatial scales, including at ward level, which Brown and Hincks and ECOTEC used as base units in the definition of their respective HMAs.

Table 4: Summary of the Datasets Used in the North West Studies

\begin{tabular}{|c|c|c|c|c|c|c|}
\hline Study & $\begin{array}{l}\text { Primary Data } \\
\text { Source }\end{array}$ & $\begin{array}{l}\text { Adopted } \\
\text { Spatial Scale }\end{array}$ & $\begin{array}{l}\text { Available } \\
\text { Spatial } \\
\text { Scale(s) }\end{array}$ & $\begin{array}{l}\text { Data } \\
\text { Collection } \\
\text { Method }\end{array}$ & $\begin{array}{l}\text { Coverage } \\
\text { (sample size) }\end{array}$ & $\begin{array}{l}\text { Frequency of } \\
\text { Data } \\
\text { Collection }\end{array}$ \\
\hline $\begin{array}{l}\text { ECOTEC } \\
(2006)\end{array}$ & $\begin{array}{l}\text { Special } \\
\text { Workplace } \\
\text { Statistics - } \\
2001 \text { Census } \\
\text { of } \\
\text { Population }\end{array}$ & Ward & $\begin{array}{l}\text { Output Area, } \\
\text { Ward and } \\
\text { Local } \\
\text { Authority }\end{array}$ & $\begin{array}{l}\text { Census of } \\
\text { Population } \\
\text { Survey of } \\
\text { origin and } \\
\text { destination } \\
\text { of } \\
\text { commuters }\end{array}$ & $\begin{array}{l}\text { Universal } \\
\text { targeting of } \\
\text { population } \\
\text { with an } \\
\text { estimated } \\
\text { accuracy of } \\
90-95 \%\end{array}$ & Decennial \\
\hline $\begin{array}{l}\text { Brown and } \\
\text { Hincks } \\
(2008)\end{array}$ & $\begin{array}{l}\text { Special } \\
\text { Migration } \\
\text { Statistics - } \\
2001 \text { Census } \\
\text { of } \\
\text { Population }\end{array}$ & Ward & $\begin{array}{l}\text { Output Area, } \\
\text { Ward and } \\
\text { Local } \\
\text { Authority }\end{array}$ & $\begin{array}{l}\text { Census of } \\
\text { Population } \\
\text { Survey of } \\
\text { origin and } \\
\text { destination } \\
\text { of migrants }\end{array}$ & $\begin{array}{l}\text { Universal } \\
\text { targeting of } \\
\text { population } \\
\text { with an } \\
\text { estimated } \\
\text { accuracy of } \\
90-95 \%\end{array}$ & Decennial \\
\hline $\begin{array}{l}\text { Nevin } \\
\text { Leather } \\
\text { Associates et } \\
\text { al (2008) }\end{array}$ & $\begin{array}{l}\text { Purchased } \\
\text { though HM } \\
\text { Land Registry }\end{array}$ & $\begin{array}{l}\text { Individual } \\
\text { unit sales at } \\
\text { postcode } \\
\text { sector } \\
\text { situated } \\
\text { within } \\
\text { Census } \\
\text { Output Areas }\end{array}$ & $\begin{array}{l}\text { Individual } \\
\text { housing unit } \\
\text { sales at } \\
\text { postcode } \\
\text { area, district } \\
\text { and sector }\end{array}$ & $\begin{array}{l}\text { Registration } \\
\text { of properties } \\
\text { sold with } \\
\text { Land Registry }\end{array}$ & $\begin{array}{l}\text { Dataset of } \\
\text { around } \\
1,533,000 \\
\text { sales } \\
\text { registered } \\
\text { between } \\
1996 \text { and } \\
2006\end{array}$ & Quarterly \\
\hline
\end{tabular}

The primary dataset used in the Nevin Leather Associates et al (2008) study was the 'price paid' dataset collected by the Land Registry which was supplemented with the SMS and SWS origin-destination data (Table 4). The 'price paid' dataset registers approximately 100,000 transactions per month as well as all new build sales at postcode level. The data is unadjusted which means that the nominal house prices can be aggregated from postcode level to higher spatial scales and subsequently adjusted to take account of the influence of seasonality and to reflect inflation or income. A further advantage is that the dataset does not include cases such as Right-to-Buy first sales, properties exchanged as gifts or those under Compulsory Purchase Orders (PCO) which are not necessarily reflective of 'pure' 
market functioning. However, the Land Registry data only captures limited information on property characteristics. As a result, in estimating 'neighbourhood prices', Nevin Leather Associates et al were forced into a further compromise by relying on an approach that combined the Land Registry data with a 'large battery of indicators at neighbourhood level drawn from the 2001 Census and other sources' (Nevin Leather Associates et al., 2008:48).

These datasets have many distinct advantages over alternative datasets - including the extent of their coverage and their availability at finer spatial scales - but it is evident from the review that the definition of HMAs in the three studies was constrained by data limitations. Data will always contain errors and this is the case with both the house price and origin-destination datasets. However, the most significant data constraint placed on the definition of HMAs - if it is accepted that the definition of HMAs should be underpinned by spatial arbitrage - is the absence of a comprehensive dataset in England that combines transaction, movement and property characteristic data in the way that the Sassines dataset does in Scotland.

\section{Defining Housing Market Area Boundaries}

The HMA boundaries in the three studies were defined using very different methodological approaches. All three approaches incorporated some form of technical analysis in the definition of their respective HMAs. However, the extent to which the technical components of the approaches underpinned the definition of the HMA boundaries was highly variable. Brown and Hincks define a set of HMAs that draw on a degree of stakeholder consultation but the approach was, to a large extent, empirically driven through the results of a relatively strict functional regionalisation exercise. However, there is a strong argument that the definition of HMAs should not be a purely technical process because the definition of HMAs should be responding to policy needs. The risk is that boundaries derived from the purely technical end of the spectrum may fail to respond to policy needs by not being implementable or appropriate from a practice perspective.

In addition, Brown and Hincks' boundaries were defined using all migrants recorded as moving between 2000 and 2001. However, migration within different sectors was not considered. This is a problem given that migration patterns for individuals or households in different sectors of the housing system will vary, potentially creating significantly different HMAs for different sectors. Coombes et al (2006) demonstrate the advantages (and disadvantages) of adopting an alternative dataset from the Census origin-destination migration data which breaks migrants down into tenures. This 'Moving Group' data allowed for tenure effects on migration to be disentangled.

The employment catchment areas used in the ECOTEC (2006) study were derived through the adoption of commuting threshold tests. However, the analysis did not reflect variation in the commuting patterns of different socioeconomic groups and there was a significant degree of interpretation involved in the derivation of the boundaries through a vaguely defined practice of allocating wards to HMAs based on the degree of 'overlap' in catchment areas. Nevin Leather Associates et al (2008) defined a set of HMAs using a triangulation approach of hard and soft analytical techniques. However, the approach suffered from low response rates on the consultation side of the exercise and arguably relied too heavily on softer policy interpretations in the construction of the HMA boundaries. 
In summary, in defining the HMA boundaries the three approaches all included an interpretive element in one form or another. As a result, the three approaches are all open to criticism with regards to their replicability and transparency. It is this difficulty in balancing the technical with the interpretative - in the ongoing search for policy application - that has generated uncertainty in the HMA definition process (Ferrari et al., 2011).

\section{The Geographies of Housing Market Areas in North West England}

Understandably, the adoption of different conceptual and methodological approaches in the definition exercises produced variable HMA geographies across the region. The striking feature of the spatial patterns of the HMAs defined in the three studies is the degree of variation in the number of HMAs identified. Brown and Hincks (2008) and Nevin Leather Associates et al (2008) identify comparable numbers of HMAs - 25 and 26 respectively (Figures 1 and 2) - but this contrasts significantly to the 45 HMAs defined in the ECOTEC (2006) study (Figure 3). The adoption of alternative conceptual and methodological anchors has also resulted in significant differences in the size, form and coverage of the HMAs across the three studies. What is apparent is that the HMAs tend to cut across local authority boundaries and that there is a lack of correspondence between HMA and local authority boundaries in the three studies. It has been argued that aligning HMA and administrative boundaries as far as possible would be beneficial due to the practicalities associated with monitoring and implementing housing market policies (Ferrari et al., 2011). However, the results of all three studies indicate that underlying spatial housing markets differ from local authority geographies when administrative boundary constraints are removed, demonstrating the inherent tension that exists in reconciling administrative functions with spatial processes (Figure 4). This lack of correspondence is also evident in relation to 2001 travel-to-work areas in the region. Many of the 2001 TTWAs are served by multiple HMAs in which the cross-cutting of HMA and TTWA boundaries is common (Figure 5).

Furthermore, less populated and especially rural areas have long been identified as 'problem' locations when defining functional areas (Coombes et al., 1979). Generally, the rural HMAs tend to be exceptionally large, serving isolated settlements and their surrounding hinterlands. The three studies all identify HMAs around Carlisle, Workington, Whitehaven and Barrow in Cumbria. Although there is consistency in the core settlements used in the definition of the HMAs in Cumbria, the size and coverage of these HMAs vary, some quite markedly. What is also apparent, particularly in the Brown and Hincks and Nevin Leather Associates et al studies, is the 'stretching' effect of rural areas in north Lancashire on the geographical reach of the Preston, Blackpool and Blackburn HMAs.

The North West region also contains the Lake District National Park which has specific planning and administrative functions and this adds a further layer of complexity to the definition exercise when considering the relationship between HMAs and existing spatial geographies. The boundaries of the HMAs defined in the three studies vary significantly from the Lake District National Park boundary (Figure 6). Depending on the study, between 4 and 5 HMAs are found to serve the National Park and, in the three studies, all of the HMAs serving the National Park were found to cut-across the National Park boundary. What was revealing from the review was that the unique characteristics and issues relating to National Parks in planning policy terms were not considered in the identification or assessment of the HMAs in any of the North West studies. 
Figure 1: HMAs defined by ECOTEC

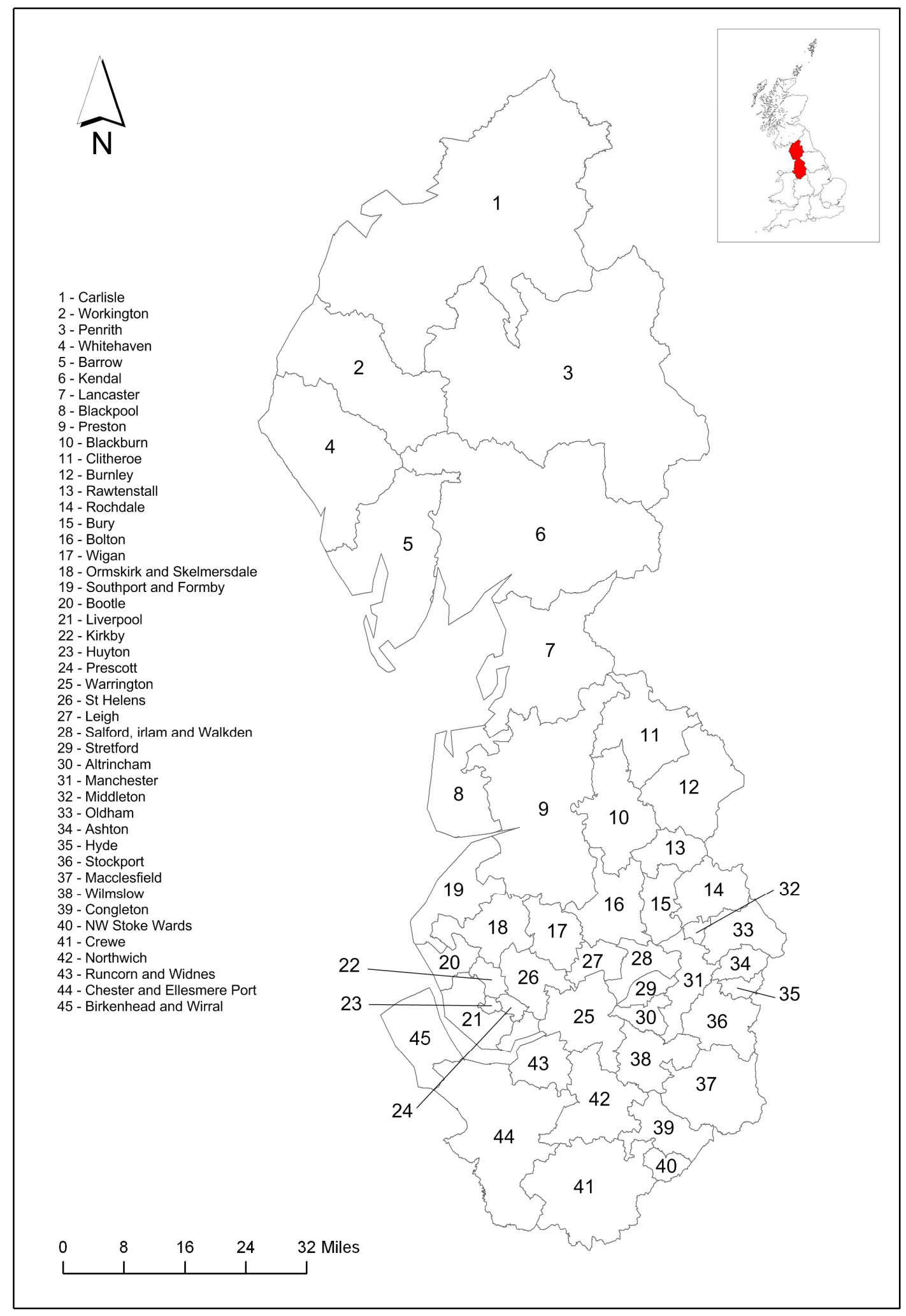


Figure 2: HMAs defined by Brown and Hincks

1 - Carlisle

2 - Workington

3 - Eden

4 - Whitehaven

5 - South Lakeland

6 - Barrow-in-Furness and Ulverston

7 - Lancaster

8- Blackpool

9 - Preston

10 - Blackburn

11 - Burnley and Nelson and Colne

12 - Rossendale

13 - Sefton and West Lancashire

14 - St Helens

15 - Wigan

16 - Bolton

17 - Bury and Salford

18 - Rochdale and Oldham

19 - Manchester

20 - Warrington

21 - Liverpool

22 - Wirral

23 - Chester

24 - Crewe and Nantwich

25 - Macclesfield

4
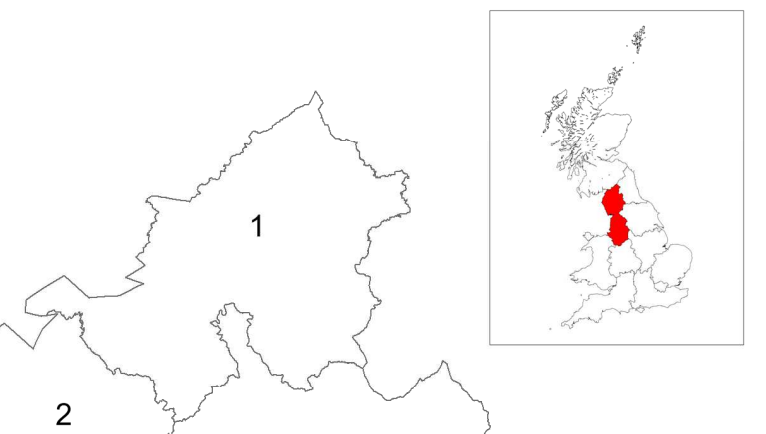

6

3

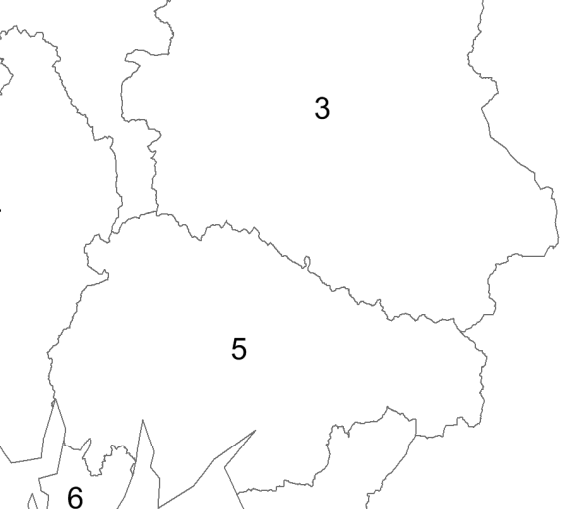

7

(1)

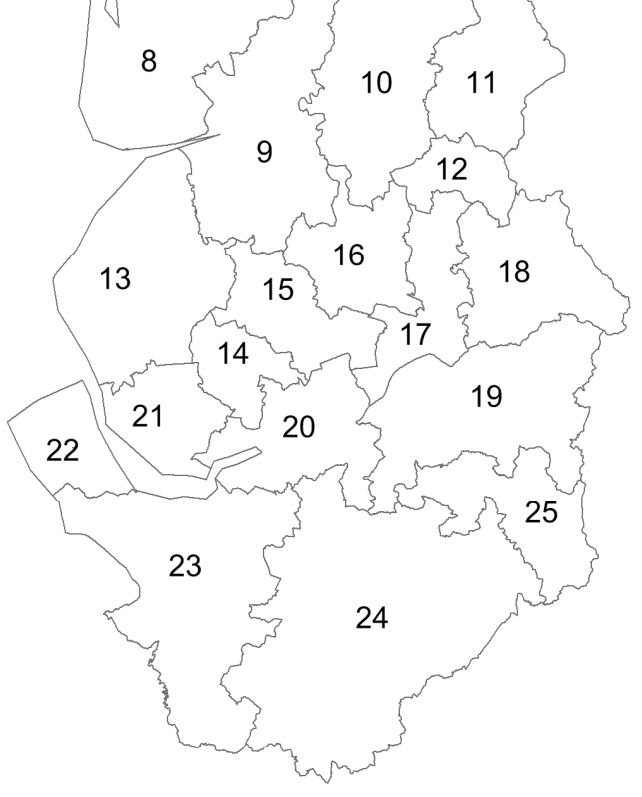


Figure 3: HMAs defined by Nevin Leather Associates et al.

1 - Carlisle

2 - Workington and Maryport

3 - North Lakes

4 - Eden Valley

5 - Copeland

6 - Central Lakes

7 - Dales and Rural Kendal

8 - Barrow. Dalton and Askham

9 - Ulverston and Cartmel

10 - Lancaster

11 - Flyde Coast

12 - Ribble Valley

13 - Central Lancashire

14 - Blackburn and Hyndburn

15 - Burnley and Pendle

16 - Rossendale

17 - Liverpool City Region North

18 - Manchester City Region West

19 - Manchester City Region North

20 - Manchester City Region Centra

21 - Manchester City Region South

22 - Liverpool City Region East

23 - West Cheshire

24 - Crewe and Nantwich

25 - Congleton

26 - Macclesfield

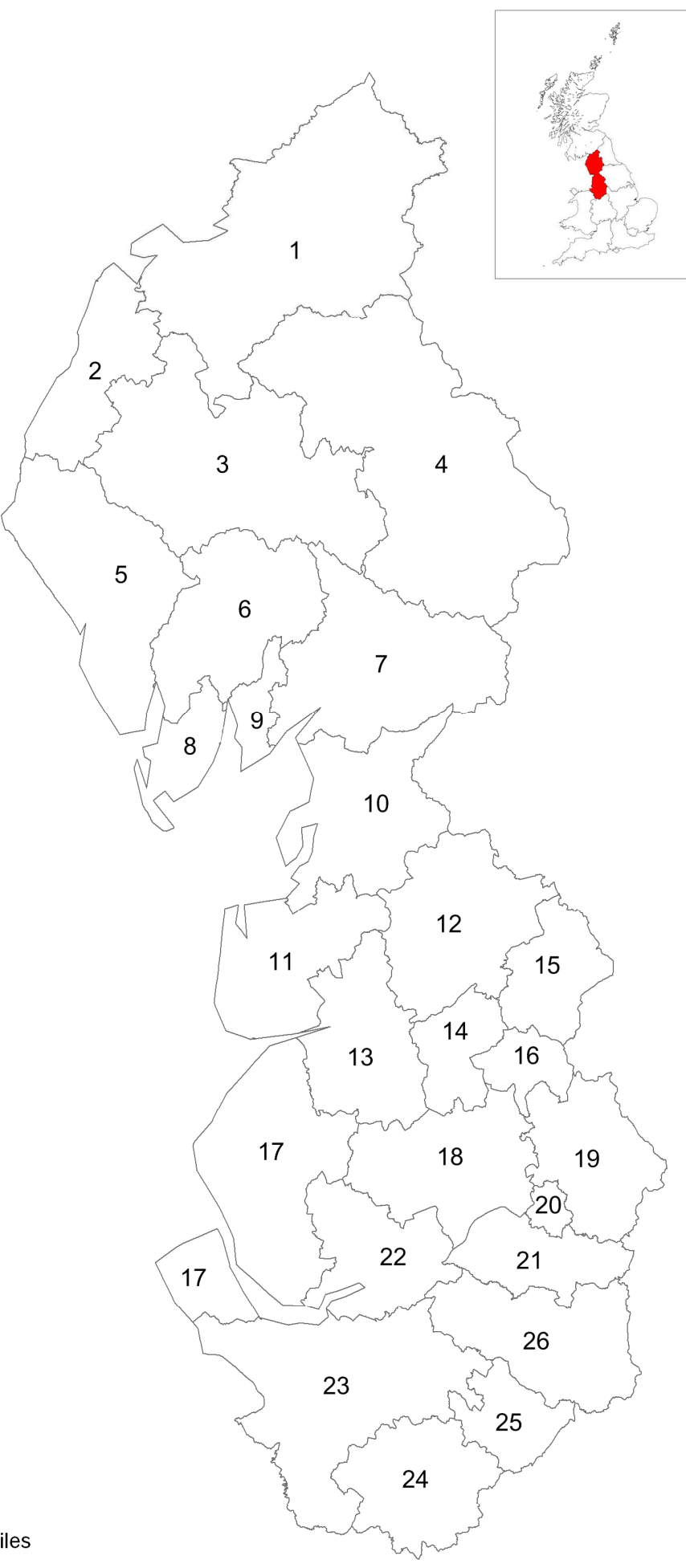


Figure: 4: HMA and Local Authority Boundaries -Example from Brown and Hincks

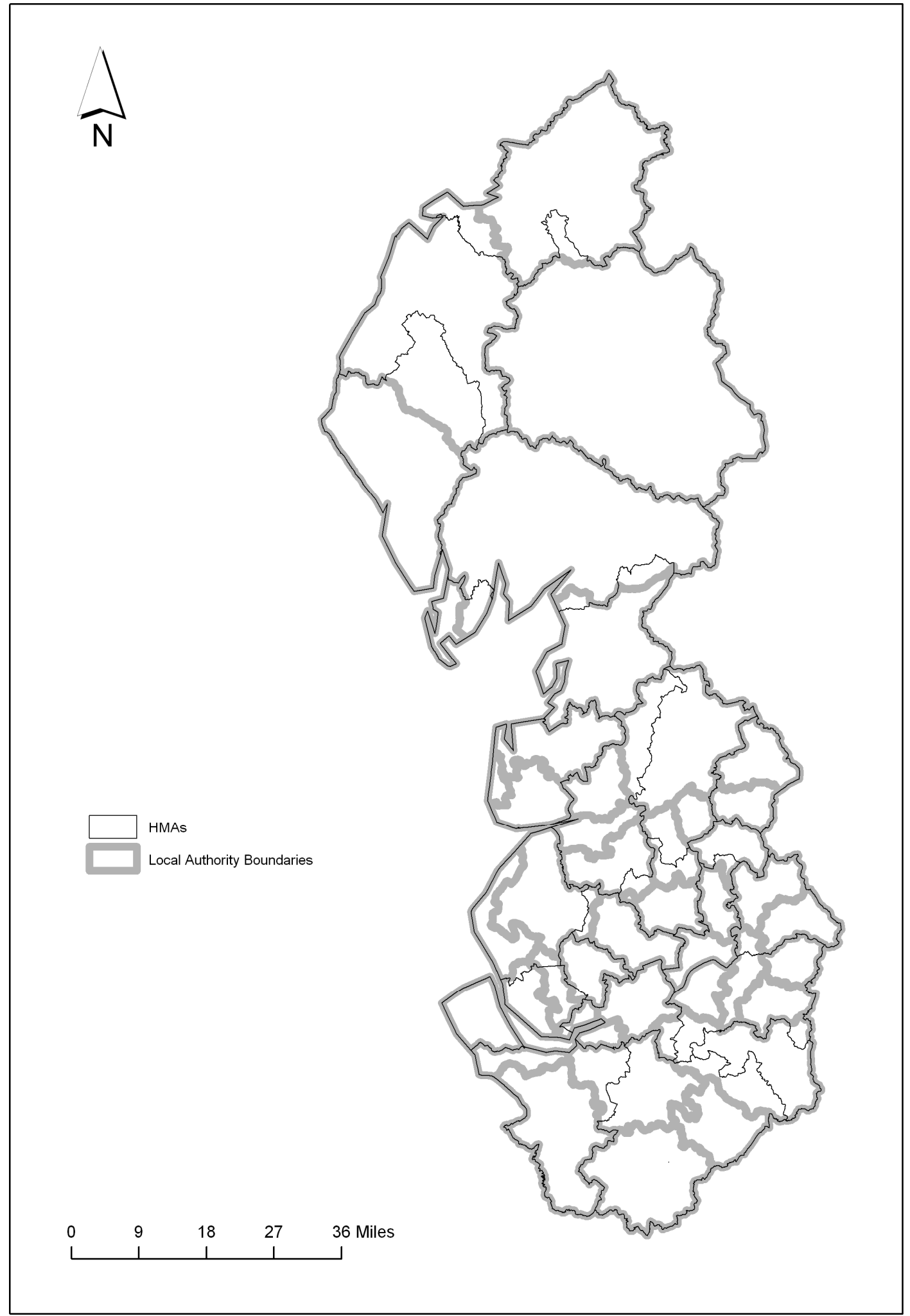


Figure 5: HMA and TTWA Boundaries -Example from ECOTEC

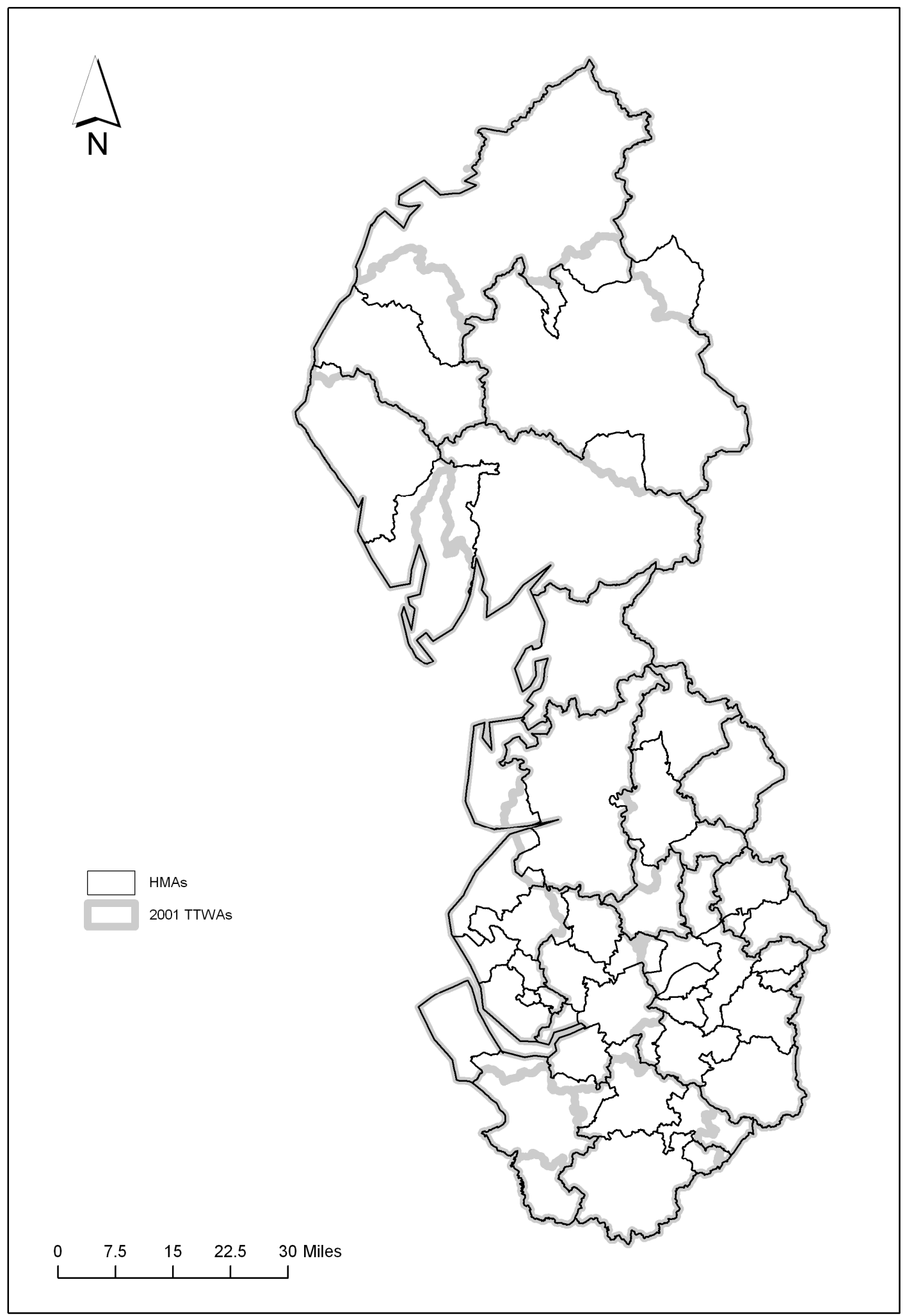


Figure: 6: HMA and the Lake District National Park Boundaries - Example from Nevin Leather Associates et al.

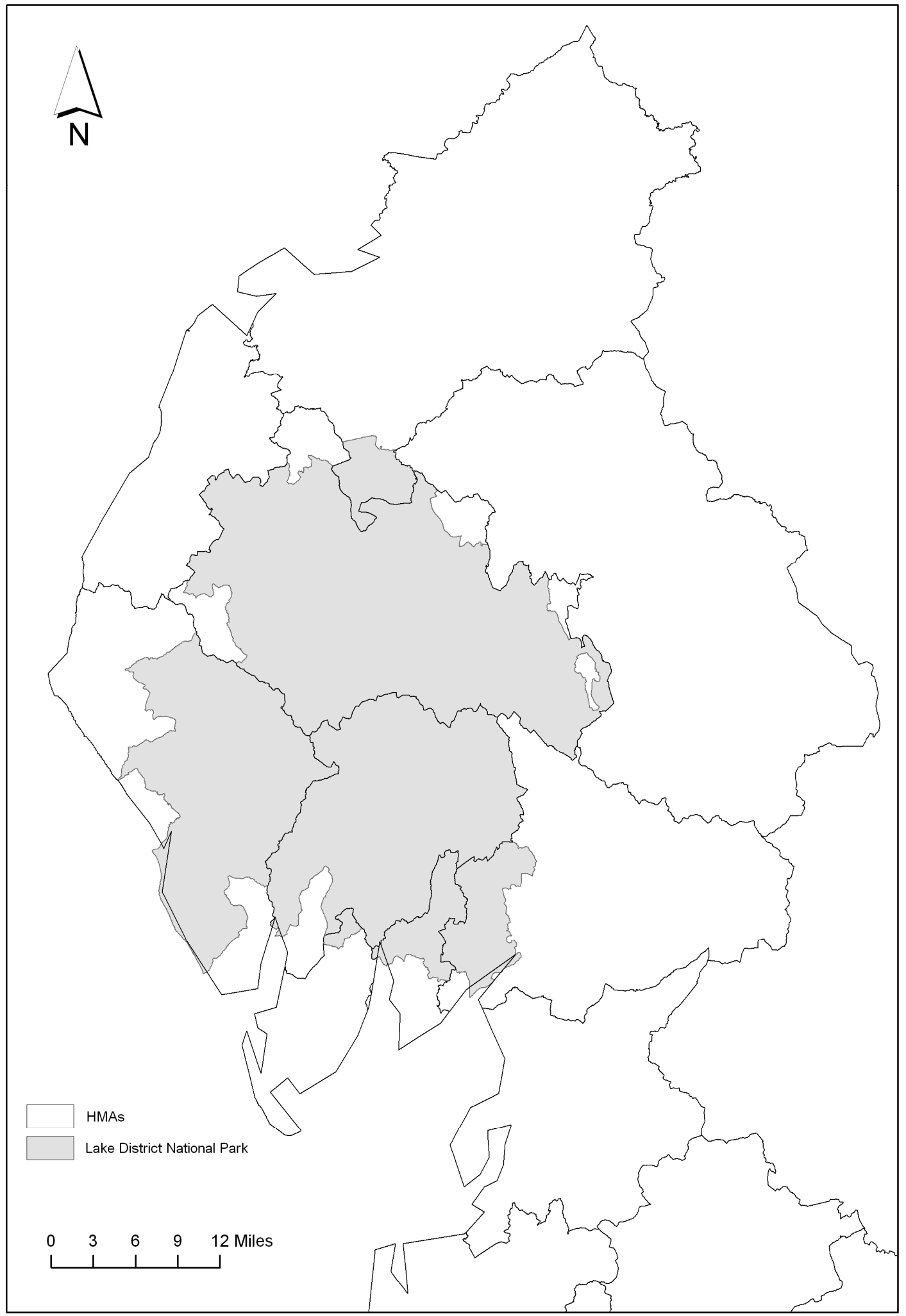




\section{Discussion and Conclusion}

This article critically reflects on the practice of defining Housing Market Areas in England. It is proposed that the definition of HMAs should be embedded within a conceptual framework that incorporates the principles of spatial arbitrage, markets search, the relationship between home and work, and considers the issue of scale. It is argued that, in an ideal scenario, market search patterns would be used to identify search hot-spots and that these hot-spots would be used to seed prospective HMAs. Following this, and reflecting the theoretical direction offered by the access-space model, commuting patterns could then be used to define upper-tier 'strategic' HMAs (Jones et al., 2010). The upper-tier HMAs would capture the spatial outcome of the home-work link on the basis that the labour market drives the housing market. Having defined the spatial limit of these upper-tier HMAs using a high level commuting self-containment threshold, the next stage would be to identify sub-tier HMAs defined using the principle of spatial arbitrage. These lower-tier HMAs would be defined based on there being a high degree of intra-HMA arbitrage and low inter-HMA arbitrage. The sub-tier HMAs would reflect the idiosyncratic nature of local housing market functionality. Ultimately, the conceptualisation recognises that housing market functioning is variegated and that unevenness in the inputs and processes underpinning housing markets provide a local articulation of outcomes that affect the form, function and structure of housing markets in space and through time.

However, as the review demonstrates - through the advancement of a typology of possible HMA approaches - the articulation of the conceptual principles that underpin the definition of HMAs, and their operationalisation in practice, is not straightforward. Indeed, it was noted that hybrid HMA approaches are likely to emerge due to the emphasis that is placed on particular conceptual principles in competing approaches and due to methodological constraints imposed on definition exercises. The result of this is a two tone typology. On the one hand there is the unconstrained approach in which idealised conceptual principles are retained and articulated through a methodology that is unaffected by constraints in the quality and collection of data or the technical approach chosen to define the HMAs. On the other hand there is the constrained approach in which the articulation of the conceptual principles and their methodological operationalisation are affected by the quality and scope of the data that is available and by the technical approach chosen to define the HMAs.

Emerging from the conceptual debates were questions that the review sought to address. First, how have the core tenets of HMA definition been applied in the studies undertaken in North West England? The review reveals that the conceptual principles that would ideally underpin the definition of HMAs have been applied variably across the three studies. The idealised approach to HMA definition - outlined in the conceptualisation - does not underpin any of the North West studies. Rather, what emerges are a set of hybrid approaches that are constrained by conceptual uncertainty and by methodological and technical limitations. The ECOTEC (2006) approach is constrained by its focus on commuting in isolation from other defining tenets but the approach was useful in demonstrating the potential value of using commuting patterns to define upper-tier HMAs. In contrast, Brown and Hincks (2008) and Nevin Leather Associates et al (2008) - whilst valuable in framing the operationalisation of the principle of arbitrage - were both constrained in their scope to apply their primary defining principle, in its purest form, due to data limitations. 
The review then went on to explore the second question: how have the HMA approaches been operationalised from a technical and methodological perspective in the North West studies? It was apparent from the review that use had been made of a range of secondary data collected by official organisations and agencies. All of these datasets had advantages in defining the HMAs in the respective studies. However, it was also argued that all of the approaches were constrained in one form or another by technical restrictions. Questions were also raised over the replicability and transparency of the approaches given the degree of interpretation that was built into the three approaches.

Finally, the review considered the question: what are the spatial geographies of HMAs that emerge as a result of the adoption of different conceptual and methodological approaches in the North West region? There were wide variations in the geographies of the HMAs defined in the three studies owing to differences in the conceptual, technical and methodological principles underpinning the three definition exercises. In addition, there was clear evidence of inconsistencies between existing administrative boundaries, other functional geographies and the HMAs defined in the three studies illustrating the ongoing tension that exists between policy implementation and management and the complex reality of spatial processes that underpin housing market functioning.

It is apparent from the review that the prospect of developing a HMA approach that mirrors the idealised conceptualisation outlined earlier in the paper is unlikely to be realised, largely due to technical limitations. However, the review demonstrated that the practice of defining HMAs is not simply an administrative exercise. The emergence of competing HMA definitions has introduced uncertainty into the practice of defining and applying HMAs for housing market analysis. The question that this raises is whether the development and application of a national multi-tier system of HMAs - which is defined in a consistent way based on economic principles (see Jones et al, 2010) - would provide analysts with a framework within which to undertake applied housing market analysis? Arguably, a consistently defined set of HMAs - albeit, as this review has demonstrated, within the limits posed by methodological and technical restrictions - would help to enhance the value of the evidence-bases being generated through Strategic Housing Market Assessments, which have been criticised for being underpinned by inconsistently defined HMAs (Ferrari et al., 2011). 


\section{References}

Adams, D. and Watkins, C. (2002) Greenfields, Brownfields and Housing Development. Oxford, Blackwell.

Alonso, W. (1964) Location and Land Use. Massachusetts, Harvard University Press.

Bibby, P. (2005) West Midlands Regional Housing Strategy 2005: Defining Housing Market Areas. Sheffield, Department of Town and Regional Planning, University of Sheffield.

Brown, P. J. B. and Hincks, S. (2008) 'A Framework for Housing Market Area Delineation: Principles and Application' Urban Studies, 45, 11, 2203-2223.

Carmona, M., Carmona, S. and Gallent, N. (2003) Delivering New Homes. New York, Routledge.

CLG (Communities and Local Government) (2011) Draft National Planning Policy Framework. CLG, London.

Coombes, M. (2009) 'English Rural Housing Market Policy: Some Inconvenient Truths?' Planning Practice and Research, 24 (2), 211-231.

Coombes, M., Raybould, S. and Wymer, C. (2006) Housing Market Areas across the North East Region: Draft Final Report. Newcastle, Centre for Urban and Regional Development Studies, University of Newcastle.

Coombes, M.G., Dixon, J.S., Goddard, J.B., Openshaw, S. and Taylor, P.J. (1979) ‘Daily Urban Systems in Britain: from theory to practice' Environment and Planning A, 11, 565-574.

De Groot, C, Mulder, C.H. and Manting, D. (2011) 'Intentions to Move and Actual Moving Behaviour in the Netherlands' Housing Studies, 26 (3), 307-328.

DTZ Pieda (2004) Housing Market Assessment Manual. London, ODPM.

ECOTEC (2006) Study into the Identification of Housing Market Areas for the Development of the Regional Spatial Strategy in the North West. Manchester, ECOTEC.

Ferrari, E. (2011) 'Conceptualising Social Housing within the Wider Housing Market: A Vacancy Chain Model' Housing Studies, 26 (1), 95-116.

Ferrari, E., Laughlin, D.L., and Watkins, C. (2011) 'Planning and the housing market: reflections on strategic housing market assessment in England' Town Planning Review, 82 (4), 393-423.

Fielding, A. (1992) 'Migration and social mobility: South East England as an escalator region' Regional Studies (26), 1 - 15. 
Grigsby, W.G. (1963) Housing Markets and Public Policy. Philadelphia, University of Pennsylvania Press.

Healey, P. (1994) 'Urban policy and property development: the institutional relations of realestate development in an old industrial region' Environment and Planning A, 26, 177-198.

Healey, P. (1998) 'Regulating property development and the capacity of the development industry' Journal of Property Research, 15 (3), 211-227.

Hincks, S. and Wong, C. (2010) 'The Spatial Interaction of Housing and Labour Markets: Commuting Flow Analysis of North West England' Urban Studies, 47 (3), 620-649.

Jones, C. (2002) 'The definition of housing market areas and strategic planning' Urban Studies, 39, 549-564.

Jones, C. and Leishman, C. (2006) 'Spatial dynamics of the housing market' Urban Studies, 43 (7), 1041-1059.

Jones, C. and Watkins, C. (2009) Housing Markets and Planning Policy. Oxford, WileyBlackwell.

Jones, C., Coombes, M. and Wong, C. (2010) Geography of Housing Market Areas: Final Report: London, Communities and Local Government.

Jones, C., Leishman, C. and Watkins, C. (2003) 'Structural Change in a Local Urban Housing Market' Environment and Planning A, 1315-1326.

Jones, C., Leishman, C. and Watkins, C. (2004) 'Intra-Urban Migration and Housing Submarkets: Theory and Evidence' Housing Studies, 19 (2), 269-283.

Jones, C., Leishman, C. and Watkins, C. (2005) 'Housing Market Processes, Urban Housing Submarkets and Planning Policy' Town Planning Review, 76 (2), 215-233.

Maclennan, D. (1982) Housing Economics: An Applied Approach. Longman, London.

Maclennan, D. (1992) Housing Search and Choice in a Regional Housing System: New Housing in Strathclyde. A report to the Housing Research Foundation for the Scottish House Builders Federation, University of Glasgow, Glasgow.

Marsh, A. and Gibb, K. (1997) Uncertainty and expectations in the economics of housing. Occasional paper 40, Centre for Housing Research and Urban Studies. Glasgow, Glasgow University.

Meen, G, (2001) Modelling Spatial Housing Markets. Dordrecht, Kluwer Academic.

Nevin Leather Associates, Inner City Solutions, and University of Sheffield (2008) The definition of housing market areas in the North West region. Wigan, NWRA. 
Ommeren, J.N., Rietveld, P. and Nijkamp, P. (1997) 'Commuting: In Search of Jobs and Residences' Journal of Urban Economics, 42, 402-421.

Paraschiv, C. and Chenavaz, R. (2011) 'Sellers' and Buyers' Reference Point Dynamics in the Housing Market' Housing Studies, 26 (3), 329-352.

Rothenberg, J., Galster, G., Butler, R, and Pitkin, J, (1991) The Maze of Urban Housing Markets: Theory, Evidence and Policy. University of Chicago Press, Chicago.

Rouwendal, J. (2004) 'Search Theory and Commuting Behaviour' Growth and Change, 35 (3), 391-418.

Rydin, Y. (2007) 'Indicators as a governmental technology? The lessons of community-based sustainability indicators projects' Environment and Planning $D, 25,610-624$.

Simon, H.A. (1984) "On the behavioural and rational foundations of economic dynamics" Journal of Economic Behaviour and Organization, 5, 35-55.

Stillwell, J. and Duke-Williams, O. (2007) 'Understanding the 2001 UK Census Migration and Commuting Data: the effects of small cell adjustment and problems of comparison with 1991' Journal of the Royal Statistical Society A, 170 (2), 425-445.

Watkins, C.A. (2001) 'The definition and identification of housing submarkets' Environment and Planning $A, 33,2235-2253$.

Wheaton, W.C. (1990) 'Vacancy, Search, and Prices in a Housing Market Matching Model' Journal of Political Economy, 98 (6), 1270-1292.

Wingo, L. (1961) Transportation and Land Use. Baltimore, Johns Hopkins University Press. 


\footnotetext{
' Since the 1980s, planning authorities in Scotland have been required to identify sub-regional housing market areas (HMAs) for the purpose of determining housing land requirements in Structure and Local Plans (Jones, 2002).

ii In May 2010, the UK General Election was held. The result was a hung parliament. Not long after, the Conservative and Liberal Democrat parties agreed to form a Coalition Government.

iii The research formed part of a collaborative project undertaken with Herriot-Watt, Newcastle, Manchester, and Sheffield Universities for the National Housing and Planning Advice Unit. The project had the aim of constructing a HMA geography for England that satisfied recent guidance, theory, and best practice and which could be used for monitoring affordability and other local housing market trends in England.

iv The National Housing and Planning Advice Unit (NHPAU) was an arms length government agency with the remit of tackling housing affordability problems. Since the research was completed, the NHPAU has been abolished.

${ }^{v}$ Since this research was conducted, Government Office North West, the North West Development Agency and the North West Regional Assembly have all been abolished.

${ }^{v i}$ Registered Social Landlords are government-funded not-for-profit organisations responsible for providing affordable housing. The term RSL is used generically to include housing associations, trusts and cooperatives who work with local authorities to provide housing. RSLs also act as a landlord and are responsible for up keeping properties and managing rents.

vii There is an opportunity to augment migration analysis with Central Health Index (CHI) data which has recently been undertaken in Northern Ireland. The $\mathrm{CHI}$ is gathered through a survey of households registering with a new GP.
} 